\title{
Self-Reported Practices in Opioid Management of Chronic Noncancer Pain: An Updated Survey of Canadian Family Physicians
}

\author{
Andrea D. Furlan ${ }^{1,2,3, *(\mathbb{D})}$, Santana Diaz ${ }^{3} \mathbb{D}$, Angela Carol ${ }^{4}\left(\mathbb{D}\right.$, Peter MacDougall ${ }^{5}$ and \\ Michael Allen ${ }^{6}$ \\ 1 KITE Toronto Rehabilitation Institute, University Health Network, Toronto, ON M5G 2A2, Canada \\ 2 Institute for Work \& Health, 400 University Ave Suite 1800, Toronto, ON M5G 1S5, Canada \\ 3 Institute of Medical Sciences, University of Toronto, Toronto, ON M5S 1A8, Canada; \\ santhanna.diaz@gmail.com \\ 4 Family Medicine, Faculty of Health Sciences, McMaster University, Hamilton, ON L8P 1H6, Canada; \\ acarol@cpso.on.ca \\ 5 Department of Anesthesia, Pain Management \& Perioperative Medicine, Dalhousie University, \\ Halifax, NS B3H 4R2, Canada; pcmacdou@gmail.com \\ 6 Continuing Professional Development, Dalhousie University, Halifax, NS B3H 4R2, Canada; \\ michael.allen@dal.ca \\ * Correspondence: andrea.furlan@uhn.ca; Tel.: +1-(416)-597-3422 (ext. 4607)
}

Received: 11 August 2020; Accepted: 12 October 2020; Published: 14 October 2020 updates

\begin{abstract}
Chronic pain affects one in five Canadians, and opioids continue to be prescribed to $12.3 \%$ of the Canadian population. A survey of family physicians was conducted in 2010 as a baseline prior to the release of the Canadian Opioid Guideline. We repeated the same survey with minor modifications to reflect the updated 2017 opioid prescribing guideline. The online survey was distributed in all provinces and territories in both English and French. There were 265 responses from May 2018 to October 2019, 55\% of respondents were male, 16\% had advanced training in pain management, $51 \%$ had more than 20 years in practice, $54 \%$ wrote five or fewer prescriptions of opioids per month, and $58 \%$ were confident in their skills in prescribing opioids. Of the 11 knowledge questions, only two were correctly selected by more than $80 \%$ of the respondents. Twenty-nine physicians (11\%) do not prescribe opioids, and the main factor affecting their decisions were concerns about long-term adverse effects and lack of evidence for effectiveness of opioids in chronic noncancer pain. Of the 12 guideline-concordant practices, only two were performed regularly by $90 \%$ or more of the respondents: explain potential harms of long-term opioid therapy and beginning dose of less than $50 \mathrm{mg}$ of morphine equivalent daily. This survey represents a small proportion of family physicians in Canada and its generalizability is limited. However, we identified a number of opioid-related and guideline-specific gaps, as well as barriers and enablers to prescribing opioids and adhering to the guideline.
\end{abstract}

Keywords: opioids; guidelines; family physicians; primary care; survey

\section{Introduction}

Chronic noncancer pain (CNCP) continues to be a major health problem affecting one in five Canadians [1]. Opioids are frequently prescribed to alleviate pain and improve function in patients with $\mathrm{CNCP}$, although there is limited evidence for effectiveness beyond three months of long-term opioid therapy [2]. 
In Canada, from 2013 to 2018 there were fewer people being prescribed opioids (14.3\% to $12.3 \%$ ), fewer people starting opioids (9.5\% to $8.1 \%$ ), fewer people being prescribed opioids on a long-term basis $(19.8 \%$ to $17.6 \%)$, more people stopping long-term opioid therapy (18.3\% to $20.4 \%)$, and more people on long-term opioid therapy were being prescribed smaller doses (72.1\% to $76.3 \%)$. However, the dosage and duration of opioid therapy among people starting opioids remained relatively stable [3].

Despite the reduction of available opioids in Canada, the number of opioid-related emergency visits, overdoses, and deaths continues to climb. Between January 2016 and December 2019 there were 15,393 apparent opioid-related deaths in Canada, with recent estimates indicating that $9.6 \%$ of Canadian adults who use opioid medications in 2018 reported some form of problematic use [4,5]. However, among people who died from illicit drug overdose in the Canadian Province of British Columbia between 2015 and 2017, 85.5\% had opioids relevant to death on toxicology; of these, both prescribed-only opioids (2.4\%) and a combination of prescribed and nonprescribed opioids $(7.8 \%)$ were relatively rare, suggesting that the majority of opioids are from illicit sources [6].

A survey of Canadian family physicians practices in opioid management of $\mathrm{CNCP}$ was conducted in 2010 [7], the year the first Canadian Opioid Guideline was released by the National Opioid Use Guideline Group (NOUGG) [8]. In 2017, an update for the guideline was released [9].

The objectives of this study are to repeat the survey to (1) determine current physicians' practices and knowledge in prescribing opioids for $\mathrm{CNCP}$ in relation to the updated Canadian opioid guideline; (2) identify changes from the survey conducted in 2010; and (3) determine adherence to the guideline, and barriers and facilitators for physicians in prescribing opioids for $\mathrm{CNCP}$ and adhering to the guideline's recommendations.

\section{Methods and Materials}

\subsection{Survey Methods}

This survey included family physicians who manage patients with CNCP and who practice medicine in any Canadian province. An online survey in English and French was hosted at Survey Monkey ${ }^{\circledR}$ and was sent to the medical regulatory authorities of Canada and the College of Family Physicians of Canada for distribution. These organizations used electronic and print newsletters, magazines, and social media with embedded links to the survey to their respective constituents. The number of physicians who received the invitation to complete the survey is unknown, but we know that in 2018, there were approximately 45,000 family medicine physicians in Canada [10]. Given the lack of a discrete sampling frame and the varied methods of contacting family physicians, a nonprobability convenience sample was obtained.

The invitation and introduction to the survey specified that participants consent to their participation by answering the questions provided and gave the option to exclude themselves if they do not prescribe opioids for CNCP. In this case, they would skip most questions about self-reported practices and would only answer questions about knowledge, barriers, and facilitators. Examples of weak and strong opioids were provided: weak opioids-codeine, tramadol, propoxyphene, meperidine. and pentazocine; strong opioids-morphine, oxycodone, hydromorphone, transdermal fentanyl, and methadone.

The survey was open from May 2018 to October 2019. There was no incentive for completing the survey. To identify rural or urban settings, a question asked if the second digit of their postal code was zero (rural) or not zero (urban). The University of Toronto Research Ethics Board approved the study.

\subsection{Modifications to the 2010 Survey}

We repeated the 2010 online survey with minor revisions to some questions, and we added questions that are related to new topics included in the 2017 guideline. The methods and results of the 2010 survey are described elsewhere [7]. 
The main changes to the survey were related to the watchful dose and opioid tapering. The 2010 guideline had introduced the term "watchful dose" of opioids, the daily dose of $200 \mathrm{mg}$ morphine equivalents at which patients may need to be reassessed or more closely monitored. The 2017 guideline eliminated the term and changed the dose to $90 \mathrm{mg}$ of morphine equivalents per day or more. The $90 \mathrm{mg}$ dose was introduced as a "strong recommendation" for CNCP patients beginning long-term opioid therapy to restrict the dose to less than $90 \mathrm{mg}$ of morphine equivalents daily rather than having no upper limit or a higher limit on dosing. In addition, there was another "weak recommendation" for patients with $\mathrm{CNCP}$ who are currently using $90 \mathrm{mg}$ morphine equivalents daily or more to taper the opioid to the lowest effective dose, potentially discontinuing the opioid therapy.

In the demographic characteristics section, we added one new question: "Wait time for second opinion regarding $90 \mathrm{mg}$ morphine equivalent daily", and we added an alternative response in three questions: "I don't have this available" (Table 1).

Table 1. Demographics and practice characteristics of respondents.

\begin{tabular}{|c|c|c|c|c|}
\hline \multirow{2}{*}{ Response } & \multicolumn{2}{|c|}{2018} & \multicolumn{2}{|r|}{2010} \\
\hline & $n(\%)$ & Total Responses, $n$ & $\%$ & Total Responses, $n$ \\
\hline Sex & & 185 & & 622 \\
\hline Male & $103(55)$ & & 59 & \\
\hline Female & $81(44)$ & & 41 & \\
\hline Prefer not to answer & $1(1)$ & & NA & \\
\hline \multirow{2}{*}{$\begin{array}{l}\text { Have advanced training in pain } \\
\text { management }\end{array}$} & & 185 & & 627 \\
\hline & $29(16)$ & & 15 & \\
\hline Years in practice & & 185 & & 621 \\
\hline $1-5$ & $31(17)$ & & 17 & \\
\hline $6-10$ & $18(10)$ & & 9 & \\
\hline $11-20$ & $41(22)$ & & 18 & \\
\hline $21-30$ & $49(26)$ & & 31 & \\
\hline$>30$ & $46(25)$ & & 26 & \\
\hline $\begin{array}{l}\text { Population of practice } \\
\text { community }\end{array}$ & & 185 & & 622 \\
\hline$<5000$ & $30(16)$ & & 13 & \\
\hline $5000-25,000$ & $43(23)$ & & 22 & \\
\hline$>25,000-100,000$ & $23(12)$ & & 14 & \\
\hline$>100,000-500,000$ & $62(34)$ & & 26 & \\
\hline$>500,000$ & $27(15)^{\dagger}$ & & 26 & \\
\hline Patients seen per month & & 185 & & 592 \\
\hline$<200$ & $53(29)$ & & 23 & \\
\hline $200-400$ & $67(36)$ & & 33 & \\
\hline$>400-600$ & $41(22)$ & & 29 & \\
\hline$>600-800$ & $18(10)$ & & 9 & \\
\hline$>800$ & $6(3)$ & & 6 & \\
\hline $\begin{array}{l}\text { Prescriptions for strong opioid } \\
\text { written per month }\end{array}$ & & 166 & & 548 \\
\hline $1-5$ & $90(54)$ & & 46 & \\
\hline
\end{tabular}


Table 1. Cont.

\begin{tabular}{|c|c|c|c|c|}
\hline \multirow{2}{*}{ Response } & \multicolumn{2}{|c|}{2018} & \multicolumn{2}{|r|}{2010} \\
\hline & $n(\%)$ & Total Responses, $n$ & $\%$ & Total Responses, $n$ \\
\hline $6-10$ & $46(28)$ & & 28 & \\
\hline $\begin{array}{l}\text { Prescriptions for weak opioid } \\
\text { written per month }\end{array}$ & & 168 & & 578 \\
\hline $1-5$ & $90(54)$ & & 31 & \\
\hline $6-10$ & $43(26)$ & & 31 & \\
\hline $11-20$ & $19(11)$ & & 22 & \\
\hline$>20$ & $16(10)$ & & 16 & \\
\hline $11-20$ & $16(10)$ & & 14 & \\
\hline$>20$ & $14(8)$ & & 12 & \\
\hline \multicolumn{2}{|c|}{$\begin{array}{l}\text { Confidence prescribing opioids for chronic } \\
\text { noncancer pain }\end{array}$} & 265 & & 704 \\
\hline 1 Not very confident & $8(3)$ & & 3 & \\
\hline 2 & $28(11)$ & & 8 & \\
\hline 3 & $76(29)$ & & 31 & \\
\hline 4 & $111(42)$ & & 43 & \\
\hline 5 Very confident & $42(16)$ & & 15 & \\
\hline \multicolumn{2}{|c|}{$\begin{array}{l}\text { Wait time for nonurgent referral to pain specialist, } \\
\text { months }\end{array}$} & 185 & & 609 \\
\hline$<1$ & $4(2)$ & & 3 & \\
\hline $1-6$ & $40(22)$ & & 23 & \\
\hline$>6-12$ & $45(24)$ & & 28 & \\
\hline$>12$ & $44(24)$ & & $39^{+}$ & \\
\hline Don't know & $10(5)$ & & 7 & \\
\hline I don't have this available & $42(23)$ & & NA & \\
\hline \multicolumn{2}{|c|}{$\begin{array}{l}\text { Wait time for second opinion regarding } 90 \mathrm{mg} \\
\text { morphine equivalent daily }\end{array}$} & 185 & & NA \\
\hline$<1$ & $40(22)$ & & NA & \\
\hline $1-6$ & $32(17)$ & & NA & \\
\hline$>6-12$ & $19(10)$ & & NA & \\
\hline$>12$ & $14(8)$ & & NA & \\
\hline Don't know & $38(21)$ & & NA & \\
\hline I don't have this available & $42(23)$ & & NA & \\
\hline \multicolumn{2}{|c|}{$\begin{array}{l}\text { Wait time for nonurgent referral to addiction } \\
\text { specialist, months }\end{array}$} & 185 & & 623 \\
\hline$<1$ & $25(14)$ & & 7 & \\
\hline $1-6$ & $55(30)$ & & 26 & \\
\hline$>6-12$ & $18(10)$ & & $21^{\dagger}$ & \\
\hline$>12$ & $26(14)$ & & 18 & \\
\hline Don't know & $34(18)$ & & $28^{\dagger}$ & \\
\hline I don't have this available & $27(15)$ & & NA & \\
\hline
\end{tabular}

NA: not applicable, this was a new question included only in the 2018 survey. ${ }^{\dagger}$ Difference is $10 \%$ or larger. 
There were three new questions added to the knowledge section: One new open-ended question about the minimum daily dose of opioid in morphine equivalent that the patient would be taking before the physician would prescribe transdermal fentanyl. This topic was related to the 2017 opioid guideline. The other two new questions were not directly related to the opioid guideline (opioid replacement therapy and one about medical cannabis). These two questions were included as the members of our team who work with regulatory authorities are collaborating in the development of educational materials for physicians.

We had noticed that in the 2010 survey $65 \%$ of respondents selected the wrong answer to what was considered a clinically significant reduction in pain intensity, perhaps because this was a tricky question, as the opioid guideline recommended a 30\% reduction in pain be considered clinically significant. We therefore revised this knowledge question "A $20 \%$ reduction in pain intensity is considered clinically significant" in the 2010 survey to "A 30\% reduction in pain intensity is considered clinically significant" in the 2018 survey.

\subsection{Data management and Analyses}

Questions regarding physicians' practices listed recommended practices and asked respondents how frequently they performed each practice (never, $<25 \%,<50 \%,>50 \%,>75 \%$, and always). For these questions, the percentage of respondents performing these practices is reported in three categories: never and $<25 \%$ of patients, $25 \%$ to $75 \%$ of patients, and $>75 \%$ and always.

Questions regarding physicians' knowledge asked if they agreed, disagreed, or had no opinion about various statements.

Questions regarding barriers and enablers to prescribing opioids and adhering to the guideline asked respondents to rate the importance of various factors on a 5 -point Likert scale $(1=$ not very important, 5 = very important). For each factor, the per cent of response is reported in three categories: 1 and 2 (not important), 3 (neutral), and 4 and 5 (important).

Analysis was performed with Microsoft Excel ${ }^{\circledR}$. We considered a difference of absolute 10 percentage points or larger to be meaningful between the surveys in 2010 and 2018. The complete survey is available in English and French (Supplementary Materials S1 and S2).

\section{Results}

\subsection{Responses}

We received 265 responses, all of which were in English. Responses according to province were Saskatchewan, $n=117(63 \%)$; Alberta, $n=30(16 \%)$; British Columbia, $26(14 \%)$; Ontario, $8(4 \%)$; Manitoba, $2(1 \%)$; Nova Scotia, $1(1 \%)$; and Yukon, $1(1 \%)$. There were no responses from New Brunswick, Newfoundland and Labrador, Northwest Territories, Nunavut, Prince Edward Island, or Quebec. Fifty-six of the 185 (30\%) respondents were from rural areas.

Demographic and practice variables for all participants are shown in Table 1. Not all respondents answered all questions. Fifty-five per cent were male, 51\% had more than 20 years in practice, $65 \%$ see less than 400 patients per month, $54 \%$ wrote five or fewer prescriptions for opioids per month, and $58 \%$ were confident in their skills in prescribing opioids for CNCP.

\subsection{Access to Physicians with Expertise in Pain and/or Addiction Medicine}

Twenty-four percent responded that the wait time for nonurgent referral to a pain specialist is longer than 12 months and $23 \%$ do not have access to a pain specialist. Regarding access to a second opinion about patients on high dose opioids ( $>90 \mathrm{mg}$ of morphine equivalent daily), $23 \%$ of respondents do not have this available to them, and $22 \%$ responded they would have this available in less than one month. The wait time for nonurgent referral to addiction medicine was less than 6 months among $44 \%$ of respondents; however, $15 \%$ do not have access to this service (Table 1 ). 


\subsection{Knowledge of Opioids}

Table 2 shows responses to the 11 knowledge questions. Only two questions were correctly selected by more than $80 \%$ of the respondents. The proportion of correct answers varied from $23 \%$ to $89 \%$ with an average of $55 \%$.

Table 2. Knowledge regarding opioid use in chronic noncancer pain (CNCP). Shown in decreasing order of correct answers in the 2018 survey.

\begin{tabular}{|c|c|c|c|c|c|}
\hline & \multirow{2}{*}{ Year } & \multicolumn{3}{|c|}{ Frequency of Response, \% } & \multirow{2}{*}{$\begin{array}{c}\text { Total } \\
\text { Responses, } n\end{array}$} \\
\hline & & Disagree & Agree & No Opinion & \\
\hline $\begin{array}{l}\text { A } 20 \% \text { reduction in pain intensity is } \\
\text { considered clinically significant } \\
\text { (2010). A 30\% reduction in pain } \\
\text { intensity is considered clinically } \\
\text { significant (2018). }\end{array}$ & $\begin{array}{l}2010 \\
2018\end{array}$ & $\begin{array}{l}18^{*} \\
5^{+}\end{array}$ & $\begin{array}{c}65 \\
89^{*,+}\end{array}$ & $\begin{array}{l}17 \\
6^{+}\end{array}$ & $\begin{array}{l}604 \\
167\end{array}$ \\
\hline $\begin{array}{l}\text { Pain relief is a more important } \\
\text { indicator of opioid effectiveness } \\
\text { than functional ability }\end{array}$ & $\begin{array}{l}2010 \\
2018\end{array}$ & $\begin{array}{l}81 * \\
86^{*}\end{array}$ & $\begin{array}{c}11 \\
7\end{array}$ & $\begin{array}{l}9 \\
7\end{array}$ & $\begin{array}{l}604 \\
167\end{array}$ \\
\hline $\begin{array}{l}\text { (NEW) Opioid replacement therapy } \\
\text { is effective for patients with opioid } \\
\text { abuse disorder }\end{array}$ & $\begin{array}{l}2010 \\
2018\end{array}$ & $\begin{array}{l}\text { NA } \\
14\end{array}$ & $\begin{array}{l}\text { NA } \\
71^{*}\end{array}$ & $\begin{array}{l}\text { NA } \\
15\end{array}$ & $\begin{array}{l}\text { NA } \\
168\end{array}$ \\
\hline $\begin{array}{l}\text { There is evidence from RCTs that } \\
\text { opioids are effective in short-term } \\
\text { (up to } 3 \text { months) relief of CNCP }\end{array}$ & $\begin{array}{l}2010 \\
2018\end{array}$ & $\begin{array}{c}8 \\
17\end{array}$ & $\begin{array}{l}75^{*} \\
68^{*}\end{array}$ & $\begin{array}{l}17 \\
15\end{array}$ & $\begin{array}{l}603 \\
168\end{array}$ \\
\hline $\begin{array}{l}\text { Patients may be safely switched } \\
\text { from a high dose of codeine to a } \\
\text { fentanyl patch }\end{array}$ & $\begin{array}{l}2010 \\
2018\end{array}$ & $\begin{array}{l}39^{*} \\
65^{*,+}\end{array}$ & $\begin{array}{c}46 \\
16^{+}\end{array}$ & $\begin{array}{l}16 \\
18\end{array}$ & $\begin{array}{l}598 \\
168\end{array}$ \\
\hline $\begin{array}{l}\text { There is evidence from RCTs that } \\
\text { opioids are effective in long-term } \\
\text { (over } 3 \text { months) relief of CNCP }\end{array}$ & $\begin{array}{l}2010 \\
2018\end{array}$ & $\begin{array}{c}13^{*} \\
53^{*,+}\end{array}$ & $\begin{array}{c}69 \\
33^{+}\end{array}$ & $\begin{array}{l}17 \\
14\end{array}$ & $\begin{array}{l}603 \\
167\end{array}$ \\
\hline $\begin{array}{l}\text { Some strong opioids provide better } \\
\text { pain relief that others }\end{array}$ & $\begin{array}{l}2010 \\
2018\end{array}$ & $\begin{array}{c}21^{*} \\
42^{*}+,\end{array}$ & $\begin{array}{c}71 \\
48^{+}\end{array}$ & $\begin{array}{c}9 \\
11\end{array}$ & $\begin{array}{l}603 \\
168\end{array}$ \\
\hline $\begin{array}{l}\text { Controlled-release opioids are more } \\
\text { effective in controlling pain than } \\
\text { immediate-release opioids }\end{array}$ & $\begin{array}{l}2010 \\
2018\end{array}$ & $\begin{array}{r}27^{*} \\
38^{*,+}\end{array}$ & $\begin{array}{c}63 \\
50^{+}\end{array}$ & $\begin{array}{l}10 \\
11\end{array}$ & $\begin{array}{l}602 \\
168\end{array}$ \\
\hline $\begin{array}{l}\text { Controlled-release opioids have a } \\
\text { lower risk of addiction than } \\
\text { immediate release opioids }\end{array}$ & $\begin{array}{l}2010 \\
2018\end{array}$ & $\begin{array}{l}30 * \\
35 *\end{array}$ & $\begin{array}{l}64 \\
58\end{array}$ & $\begin{array}{l}6 \\
8\end{array}$ & $\begin{array}{l}605 \\
168\end{array}$ \\
\hline $\begin{array}{l}\text { (NEW) Medical cannabis is effective } \\
\text { for neuropathic pain }\end{array}$ & $\begin{array}{l}2010 \\
2018\end{array}$ & $\begin{array}{l}\text { NA } \\
26\end{array}$ & $\begin{array}{l}\text { NA } \\
35^{*}\end{array}$ & $\begin{array}{l}\text { NA } \\
39\end{array}$ & $\begin{array}{l}\text { NA } \\
168\end{array}$ \\
\hline $\begin{array}{l}\text { Some strong opioids are more likely } \\
\text { to lead to addiction than others }\end{array}$ & $\begin{array}{l}2010 \\
2018\end{array}$ & $\begin{array}{l}28 * \\
23 *\end{array}$ & $\begin{array}{l}63 \\
72\end{array}$ & $\begin{array}{l}9 \\
5\end{array}$ & $\begin{array}{l}603 \\
168\end{array}$ \\
\hline
\end{tabular}

Correct answers $\left({ }^{*}\right)$. RCT: Randomized controlled trial. ${ }^{\dagger}$ Difference is $10 \%$ or larger. "NEW" indicate new statements added to survey in conducted in 2010. NA: not applicable.

The question about the minimum daily dose of opioid in morphine equivalent that the patient would be taking before the physician would prescribe transdermal fentanyl was correctly answered by 80 physicians ( $48 \%$ ). Thirty-five physicians ( $21 \%$ ) incorrectly responded that "there is no minimum dose, it varies with patient condition", 12 physicians $(7 \%)$ incorrectly responded that the minimum is $40 \mathrm{mg}$, and 7 physicians (4\%) incorrectly responded that the minimum was $20 \mathrm{mg}$. Twenty percent of physicians $(n=34)$ had no opinion about this question. No physician responded that transdermal fentanyl is their first line of opioid for CNCP.

There was one new question in the 2018 survey that showed a high response of physicians with "no opinion", which was 39\% to "Medical cannabis is effective for neuropathic pain". Only 35\% selected the correct response of "agree" with this statement. 


\subsection{Opioid Prescribing Practices}

Seventy percent $(n=185)$ of respondents prescribed both weak and strong opioids. Eleven percent $(n=29)$ did not prescribe opioids, $16 \%(n=43)$ prescribed only weak opioids, and $3 \%(n=8)$ prescribed only strong opioids.

Table 3 shows the results regarding factors affecting decisions not to prescribe opioids for CNCP among the 29 physicians who answered: "I do not prescribe opioids for CNCP." The most important factors affecting their decisions were concerns about long-term adverse effects (96\%) and lack of evidence for effectiveness of opioids in CNCP (79\%). Importantly, concerns about becoming a "target prescriber" or audit from regulatory or monitoring bodies were not major barriers, respectively, rated by $32 \%$ and $18 \%$ of the respondents.

Table 3. Rating of factors affecting decision not to prescribe opioids for chronic noncancer pain (CNCP).

Shown in decreasing order of importance in the 2018 survey.

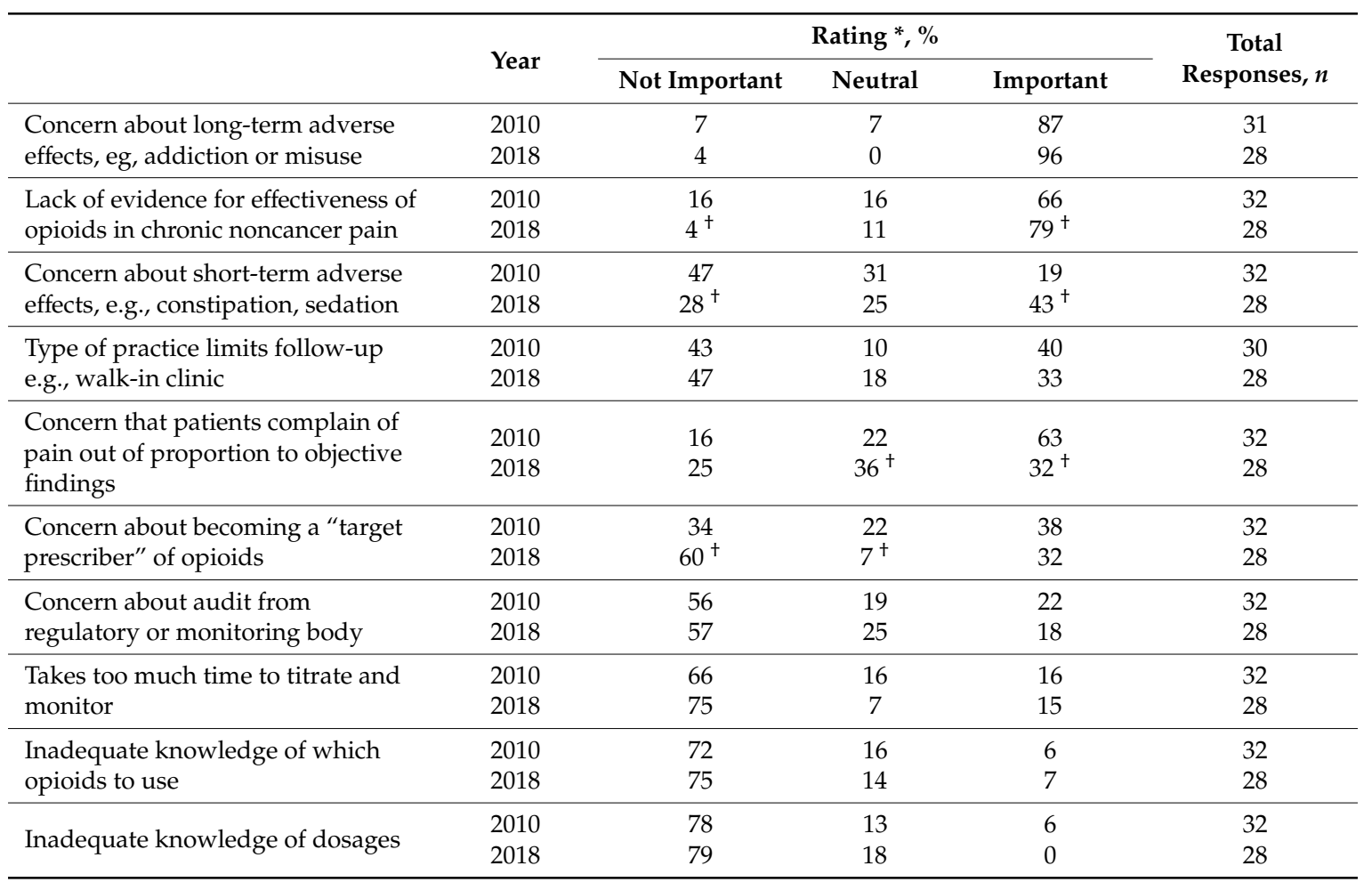

* Percent of respondents rating importance of factor as 1 or 2 (not important), 3 (neutral), or 4 or 5 (important) on 5-point Likert scale. ${ }^{+}$Difference is $10 \%$ or larger. Percentage may not total $100 \%$ because some respondents indicated "no opinion". The total of eligible participants to answer this question is 29 ("I do not prescribe opioids for $\mathrm{CNCP}^{\prime \prime}$.

Results regarding factors affecting decisions not to prescribe strong opioids for $\mathrm{CNCP}$ among the 43 physicians who answered: "I only prescribe weak opioids for CNCP" are in Supplementary Table S1. The most important factors affecting their decisions were concerns about long-term adverse effects, belief that strong opioids are commonly diverted and abused in community, and lack of evidence for effectiveness of strong opioids in CNCP. It is interesting that concerns about becoming a "target prescriber" or audit from regulatory or monitoring bodies were rated by $65 \%$ and $51 \%$ by the respondents, respectively.

\subsection{Adherence to Opioid Prescribing Guideline}

The 2017 Canadian opioid guideline defines CNCP as "any painful condition that persists for $\geq 3$ months that is not associated with a diagnosis of cancer". Only $17 \%(n=46)$ of the respondents responded that this definition is similar to their own definition of $\mathrm{CNCP}$. The majority of responses 
( $n=159,60 \%$ ) said their definition of chronic pain is "pain persisting beyond the time normally associated with healing for a specific illness or injury", and $60(23 \%)$ responded that they use "pain that persists more than 6 months".

The 29 physicians who do not prescribe opioids for CNCP were automatically skipped from seeing the following sections leaving an eligible sample of 236 participants.

Table 4 shows the frequency of following 12 guideline-concordant practices performed before starting patients on opioids for $\mathrm{CNCP}$. Fourteen practices are shown, two are new in relation to the survey conducted in 2010, and two are distracters (practices not recommended in the guideline) to reveal whether respondents tended to report they always performed the listed practices. Only two practices were performed regularly by $90 \%$ or more of the respondents: explain potential harms of long-term opioid therapy and beginning dose of less than $50 \mathrm{mg}$ of morphine equivalents daily. The number of participants who perform these practices regularly ranged from $27 \%$ to $95 \%$, with an average of $66 \%$. The two distracter questions were not performed by $122(59 \%)$ and $116(56 \%)$ of the respondents, suggesting the participants were paying attention to the survey questions.

Table 4. Frequency of following recommended practices performed before starting patients on opioids (shown in decreasing order of frequency in the 2018 survey).

\begin{tabular}{|c|c|c|c|c|c|}
\hline & \multirow{2}{*}{ Year } & \multicolumn{3}{|c|}{ Frequency of Responses, \% } & \multirow{2}{*}{$\begin{array}{c}\text { Total } \\
\text { Responses, } n\end{array}$} \\
\hline & & Never, $<25 \%$ & $25 \%$ to $75 \%$ & $>75 \%$, Always & \\
\hline \multirow{2}{*}{$\begin{array}{l}\text { Explain potential harms of } \\
\text { long-term opioid therapy }\end{array}$} & 2010 & 2 & 11 & 87 & 661 \\
\hline & 2018 & 1 & 4 & 95 & 208 \\
\hline \multirow{2}{*}{$\begin{array}{l}\text { (NEW) Be sure to prescribe a } \\
\text { dose less than } 50 \text { mg morphine } \\
\text { equivalents daily }\end{array}$} & 2010 & NA & NA & NA & NA \\
\hline & 2018 & 4 & 5 & 91 & 207 \\
\hline \multirow{2}{*}{$\begin{array}{l}\text { (NEW) Assess for past/current } \\
\text { substance use disorders as well } \\
\text { as active psychiatric disorders. }\end{array}$} & 2010 & NA & NA & NA & NA \\
\hline & 2018 & 1 & 13 & 86 & 208 \\
\hline \multirow{2}{*}{$\begin{array}{l}\text { Assess patient's level of function } \\
\text { (e.g., social, recreational, } \\
\text { occupational) }\end{array}$} & 2010 & 4 & 20 & 76 & 671 \\
\hline & 2018 & 2 & 19 & 78 & 208 \\
\hline \multirow{2}{*}{$\begin{array}{l}\text { Explain potential benefits of } \\
\text { long-term opioid therapy }\end{array}$} & 2010 & 9 & 17 & 75 & 665 \\
\hline & 2018 & 10 & 16 & 74 & 208 \\
\hline \multirow{2}{*}{$\begin{array}{l}\text { Confirm that the patient has a } \\
\text { condition that has been shown } \\
\text { to benefit from opioids }\end{array}$} & 2010 & 11 & 27 & 62 & 654 \\
\hline & 2018 & 10 & 27 & 63 & 204 \\
\hline \multirow{2}{*}{$\begin{array}{l}\text { Have patient sign a treatment } \\
\text { agreement }\end{array}$} & 2010 & 42 & 21 & 37 & 665 \\
\hline & 2018 & $15^{\dagger}$ & 23 & $62^{\dagger}$ & 207 \\
\hline \multirow{2}{*}{$\begin{array}{l}\text { Assess patient's level of pain } \\
\text { intensity using a scale }\end{array}$} & 2010 & 27 & 26 & 47 & 667 \\
\hline & 2018 & $15^{\dagger}$ & 25 & $60^{\dagger}$ & 208 \\
\hline \multirow{2}{*}{$\begin{array}{l}\text { If patient is on a benzodiazepine, } \\
\text { try to taper them off }\end{array}$} & 2010 & 21 & 35 & 44 & 650 \\
\hline & 2018 & $11^{+}$ & 30 & $59^{+}$ & 208 \\
\hline \multirow{2}{*}{$\begin{array}{l}\text { Assess risk of addiction using } \\
\text { screening tool }\end{array}$} & 2010 & 38 & 25 & 37 & 666 \\
\hline & 2018 & $24^{\dagger}$ & 25 & $51^{\dagger}$ & 207 \\
\hline \multirow{2}{*}{ Perform urine drug screening } & 2010 & 68 & 17 & 15 & 667 \\
\hline & 2018 & $31^{+}$ & 24 & $44^{+}$ & 207 \\
\hline \multirow{2}{*}{$\begin{array}{l}\text { Give the patient written } \\
\text { information about opioid } \\
\text { therapy }\end{array}$} & 2010 & 62 & 23 & 16 & 659 \\
\hline & 2018 & $47^{\dagger}$ & 26 & $27^{\dagger}$ & 208 \\
\hline \multirow{2}{*}{$\begin{array}{l}\text { (\#) Refer to colleague for } \\
\text { assessment }\end{array}$} & 2010 & 57 & 32 & 11 & 655 \\
\hline & 2018 & 59 & 32 & 9 & 207 \\
\hline \multirow{2}{*}{$\begin{array}{l}\text { (\#) Conduct formal } \\
\text { psychological screening }\end{array}$} & 2010 & 71 & 18 & 11 & 668 \\
\hline & 2018 & 56 & 25 & 19 & 208 \\
\hline
\end{tabular}

Percent of respondents indicating they perform practices never or in $<25 \%$ of their patients, in $25 \%$ to $50 \%$ of their patients, or in $>75 \%$ of their patients or always. ${ }^{+}$Difference is $10 \%$ or larger. Number of respondents per question varied from 204 to 208 physicians. (NEW) New questions added to the survey. \# Practices not recommended in guideline are included in survey as distracters to reveal whether respondents tended to report they always performed the listed practices. NA: not applicable. 
Table 5 shows the frequency of following 13 guideline-concordant practices performed while monitoring patients on opioids for CNCP. Only one practice was performed regularly by $90 \%$ of more of the participants: observing for aberrant drug-related behavior. Three practices were performed regularly by $80 \%$ to $90 \%$ of the participants: assessment for specific adverse effects, advising the patient to use caution while driving or operating machinery, and assessing the patient's level of function. The new practice added to this survey was performed regularly by $70(42 \%)$ respondents, and it is related to referring the patient to formal multidisciplinary program if the patient is experiencing a serious challenge in tapering opioid.

Table 5. Frequency of following recommended practices performed while monitoring patients on opioids (shown in decreasing order of frequency in the 2018 survey).

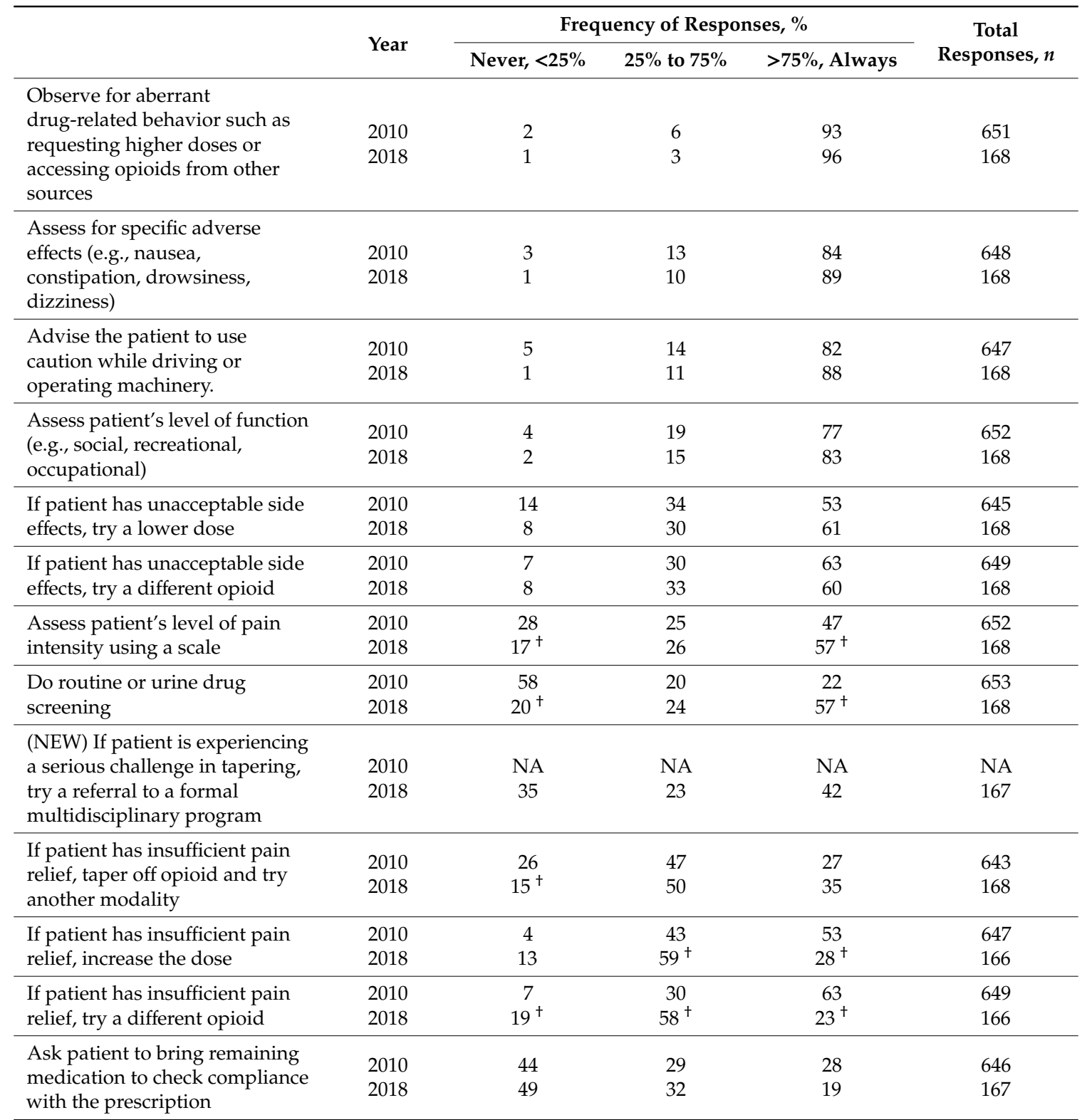

\footnotetext{
Percent of respondents indicating they perform practices never or in $<25 \%$ of their patients, in $25 \%$ to $50 \%$ of their patients, or in $>75 \%$ of their patients or always. ${ }^{\dagger}$ Difference is $10 \%$ or larger. Number of respondents per question varied from 166 to 168 physicians. (NEW) New questions added to the survey. NA: not applicable.
}

The daily dose of morphine equivalent that the respondents considered that the patient might need to be referred for a second opinion was $90 \mathrm{mg}$ by 44 physicians $(25 \%), 100 \mathrm{mg}$ by 31 physicians 
(20\%), and $200 \mathrm{mg}$ by 12 physicians (15\%). The average was $93 \mathrm{mg}$ and the median $90 \mathrm{mg}$ (See Supplementary Figure S1)

\subsection{Enabling Factors for Prescribing Opioids and for Adherence to Opioid Prescribing Guideline}

Table 6 shows physicians' ratings of factors for optimizing use of opioids for CNCP. The top 3 highest-rated factors were access to patient's opioid prescription history from a provincial monitoring program (rated useful by $88 \%$ of physicians), followed by improved access to consultants who are experts in pain or addiction (87\%) and availability of non-pharmacological options for treating CNCP $(85 \%)$. The latter was one of the new items added to this updated survey. The other new item added to this survey was rated somewhat lower (72\%): accessibility of other pharmacological agents (transdermal or sublingual buprenorphine).

Table 6. Usefulness of enabling factors for optimizing use of opioids for chronic noncancer pain (shown in decreasing order of usefulness in the 2018 survey).

\begin{tabular}{|c|c|c|c|c|c|}
\hline & & Not Useful & Neutral & Useful & $\begin{array}{c}\text { Total } \\
\text { Responses, } n\end{array}$ \\
\hline \multirow{2}{*}{$\begin{array}{l}\text { Access to patients' opioid } \\
\text { prescription history from provincial } \\
\text { monitoring program }\end{array}$} & 2010 & 5 & 4 & 87 & 646 \\
\hline & 2018 & 2 & 1 & 88 & 168 \\
\hline \multirow{2}{*}{$\begin{array}{l}\text { Improved access to consultants who } \\
\text { are experts in pain or addiction }\end{array}$} & 2010 & 5 & 8 & 84 & 646 \\
\hline & 2018 & 6 & 3 & 87 & 168 \\
\hline \multirow{2}{*}{$\begin{array}{l}\text { (NEW) Availability of non- } \\
\text { pharmacological options }\end{array}$} & 2010 & NA & NA & NA & NA \\
\hline & 2018 & 4 & 5 & 85 & 167 \\
\hline \multirow{2}{*}{$\begin{array}{l}\text { Knowledge of risks and benefits of } \\
\text { different opioids }\end{array}$} & 2010 & 4 & 10 & 84 & 650 \\
\hline & 2018 & 5 & 11 & 82 & 168 \\
\hline \multirow{2}{*}{$\begin{array}{l}\text { Tips in recognizing patients at high } \\
\text { risk of addiction }\end{array}$} & 2010 & 6 & 11 & 83 & 651 \\
\hline & 2018 & 8 & 8 & 82 & 168 \\
\hline \multirow{2}{*}{$\begin{array}{l}\text { Up to date guideline on use of } \\
\text { opioids in CNCP }\end{array}$} & 2010 & 5 & 11 & 82 & 646 \\
\hline & 2018 & 5 & 9 & 82 & 167 \\
\hline \multirow{2}{*}{$\begin{array}{l}\text { Validated scale to assess function } \\
\text { (e.g., social, recreational, functional) }\end{array}$} & 2010 & 8 & 9 & 81 & 650 \\
\hline & 2018 & 8 & 4 & 82 & 168 \\
\hline \multirow{2}{*}{$\begin{array}{l}\text { Continuing medical education in } \\
\text { optimal use of opioids in CNCP }\end{array}$} & 2010 & 7 & 13 & 79 & 643 \\
\hline & 2018 & 4 & 9 & 82 & 166 \\
\hline \multirow{2}{*}{$\begin{array}{l}\text { Knowledge of practical aspects of } \\
\text { urine drug screening (e.g., collection } \\
\text { sample, interpreting results) }\end{array}$} & 2010 & 13 & 11 & 72 & 649 \\
\hline & 2018 & 7 & 7 & $82^{+}$ & 168 \\
\hline \multirow{2}{*}{$\begin{array}{l}\text { Availability of urine drug screening } \\
\text { at local lab }\end{array}$} & 2010 & 18 & 15 & 64 & 650 \\
\hline & 2018 & 9 & 8 & $81^{\dagger}$ & 168 \\
\hline \multirow{2}{*}{ Patient education material } & 2010 & 7 & 14 & 77 & 647 \\
\hline & 2018 & 5 & 13 & 79 & 168 \\
\hline \multirow{2}{*}{$\begin{array}{l}\text { Validated screening tool to screen } \\
\text { patients for risk of addiction }\end{array}$} & 2010 & 12 & 12 & 74 & 652 \\
\hline & 2018 & 9 & 12 & 76 & 168 \\
\hline \multirow{2}{*}{$\begin{array}{l}\text { Validated scale to assess pain } \\
\text { intensity }\end{array}$} & 2010 & 12 & 12 & 74 & 649 \\
\hline & 2018 & 16 & 7 & 73 & 168 \\
\hline \multirow{2}{*}{$\begin{array}{l}\text { (NEW) Accessibility of other } \\
\text { pharmacological agents } \\
\text { (transdermal or sublingual } \\
\text { buprenorphine) }\end{array}$} & 2010 & NA & NA & NA & NA \\
\hline & 2018 & 10 & 13 & 72 & 168 \\
\hline \multirow{2}{*}{$\begin{array}{l}\text { Readily available help, such as } \\
\text { physician mentor or 1-800 help line }\end{array}$} & 2010 & 18 & 16 & 61 & 643 \\
\hline & 2018 & 17 & 11 & 68 & 167 \\
\hline
\end{tabular}

Per cent of respondents rating usefulness of factor as 1 or 2 (not useful), 3 (neutral), or 4 or 5 (useful). ${ }^{\dagger}$ Difference is $10 \%$ or larger. Percentages may not total $100 \%$ because some respondents indicated "no opinion". (NEW) indicate new factors added to survey in comparison to 2010. NA: not applicable. 


\section{Discussion}

This study is an updated survey of family physicians' practices in opioid management of CNCP in Canada. The demographic characteristics of the physicians who responded to this survey were similar to the physicians who answered the 2010 survey, except for provincial distribution. In 2010, 52\% were from Ontario, and in 2018, 63\% were from Saskatchewan. Given the non-probabilistic nature of the sample, we suggest caution in generalizing to the larger population of Canadian family physicians, as the 2018 survey might be susceptible to low response bias. The respondents of this survey were mostly male, with more than 20 years in practice, working in urban settings with small size practices. Most respondents write few prescriptions of opioids per month and they are very confident in their skills to prescribe opioids. The respondents have difficulty accessing services with expertise in pain and addiction medicine.

The average of correct responses in knowledge regarding opioids for CNCP was 55\% (range 23\% to $89 \%$ ), which has improved from 2010 where the average of participants who had achieved correct responses was 38\% (range from 13\% to 81\%) [7]. Another important aspect of knowledge is to safely switch from an oral opioid to transdermal fentanyl. In 2010, 38\% of the respondents correctly identified the minimum daily dose of opioid a patient should be taking before receiving the transdermal fentanyl $(60 \mathrm{mg})$. In the present survey, this number increased to $48 \%$ of the respondents. Similarly, in the current survey $65 \%$ of respondents correctly disagreed with the statement that patients could be safely switched from a high dose of codeine to transdermal fentanyl compared with $39 \%$ in 2010 . While these results may indicate better knowledge translation, exchange, and education regarding safe practices, they are still problematic, considering the seriousness of the situation. The new question about medical cannabis being effective for neuropathic pain showed a low rate of $35 \%$ of correct responses, and this will be important when we repeat this survey in the future to assess if this rate is improved in Canada.

Other improvements in knowledge regarding opioid use from 2010 are correctly disagreeing that some strong opioids provide greater pain relief than others (42\% correctly answered in 2018/19 vs. $21 \%$ in 2010), controlled release opioids are more effective in controlling pain than immediate release opioids ( $38 \%$ correctly answered in $2018 / 19$ vs. $27 \%$ in 2010 ), and there is RCT evidence that opioids are effective in long-term relief of CNCP (53\% correctly disagreed in 2018/19 vs. $13 \%$ in 2010).

It is possible that improved knowledge about the lack of RCT evidence for long-term relief of CNCP leads to more physicians not prescribing opioids or prescribing only weak opioids. Twenty-seven percent of family physicians surveyed do not prescribe opioids or prescribe only weak opioids an increase from the $13 \%$ found in 2010 . The unintended consequence of this finding is that it may become difficult for some patients who need legitimate opioid prescriptions to find a family physician to prescribe for them. A recent survey in Nova Scotia showed that $28 \%$ of family physicians accepting new patients would not accept a new patient if the person is on opioids [11].

In our study, the top barriers for not prescribing opioids were similar to the barriers reported in 2010 and included concerns about long-term adverse effects (95\% in 2018 and $87 \%$ in 2010) and lack of evidence for effectiveness of opioids in CNCP (79\% in 2018 and 66\% in 2010). More physicians were concerned about short-term adverse effects ( $43 \%$ in 2018 vs. 19\% in 2010), but fewer were concerned that patients complain of pain out of proportion to objective findings ( $32 \%$ in 2018 vs. $63 \%$ in 2010).

The top barriers affecting their decisions to prescribe only weak opioids (e.g., codeine or tramadol) were also similar to 2010 and included concerns about long-term adverse effects ( $88 \%$ in 2018 and $88 \%$ in 2010), belief that strong opioids are commonly diverted and abused in community (75\% in 2018 and $83 \%$ in 2010), and concern about becoming a target prescriber of opioids (65\% in 2018 and $60 \%$ in 2010). More physicians were concerned about the lack of evidence for effectiveness of strong opioids in CNCP (73\% in 2018 vs. $47 \%$ in 2010$)$.

With regards to adherence to the Canadian opioid guideline, it was expected that in 2018 a great majority of Canadian family physicians would have been exposed for enough time to the 2010 guideline, and for at least one year to the updated 2017 guideline. It was surprising to find that the respondents' definitions of chronic non-cancer pain matched the guideline by only $17 \%$ of the respondents. 
With respect to practices performed regularly before starting patients on opioids, the results showed that the top guideline-concordant practice in both surveys was to explain potential harms of long-term opioid therapy (95\% in 2018 and 87\% in 2010). However, the second and third top practices in 2018 were beginning opioid therapy with less than $50 \mathrm{mg}$ morphine equivalent per day $(91 \%$, new practice included only in the 2018 survey), and assessing for past/current substance use disorder as well as an active psychiatric disorder ( $86 \%$, new practice included only in the 2018 survey).

Several recommended practices before starting patients on opioids from the 2010 guideline were performed more frequently in the current survey: use of a signed treatment agreement increased from $37 \%$ to $62 \%$; assessing patient's level of pain using a scale increased from $47 \%$ to $60 \%$; tapering patients off benzodiazepines increased from $44 \%$ to $59 \%$, assessing risk of addiction using a screening tool increased from $37 \%$ to $51 \%$; and perhaps most notably urine drug screening increased from $15 \%$ to $44 \%$. These increases suggest that it takes many years for guidelines' recommendations or guidance statements to be implemented in practice.

With respect to practices performed while monitoring patients on opioids, the top three guideline-concordant practices were exactly the same as in 2010: observe for aberrant drug-related behavior (95\% in 2018 and 93\% in 2010), assess for adverse effects (89\% in 2018 and 84\% in 2010), and advise caution while driving or operating machinery ( $88 \%$ in 2018 and $82 \%$ in 2010). Again, urine drug screening increased markedly in 2018, from $22 \%$ in 2010 to $57 \%$ in the current survey. However, if the patient was having insufficient pain relief physicians were less likely to increase the dose of opioid ( $28 \%$ in 2018 vs. $53 \%$ in 2010 ) or try a different opioid ( $23 \%$ in 2018 vs. $40 \%$ in 2010 ). These changes and lack of changes are reassuring that physicians are following the 2017 guideline's recommendations that are much more restrictive than the 2010 guideline.

Regarding knowledge of what is the daily dose of opioids they consider a need for a second opinion, only one in four physicians agreed with the 2017 guideline that it should be $90 \mathrm{mg}$ of morphine equivalents daily. The remaining physicians thought it should be higher than 90 .

Several recommended practices were reported as having been performed more frequently since the first survey, most notably urine drug screening and use of management agreements. However, these practices are not classified as recommendations in the 2017 guideline. Rather, they are the subject of "guidance statements" that describe the uncertainty around their effectiveness.

There are many reasons why physicians may not adhere to opioid guidelines. A recent qualitative study conducted with family physicians in Ontario looked at facilitators and barriers in using the Canadian opioid guideline, and found that the guidelines were practical and pragmatic and constitute a "safety net" or "framework", while the main barriers were time and effort required to become familiar with the contents and "very labor-intensive" [12]. It is also noteworthy that much of the evidence around opioid prescribing is of low to moderate quality. The current guideline makes 10 recommendations of which only four are "strong recommendations" so physicians may feel less compelled to adhere to guidelines. Strong recommendations indicate that all or almost all fully informed patients would choose the recommended course of action which would indicate to clinicians that the recommendation is appropriate for all or almost all individuals [9].

Our survey also identified potential enablers to effective opioid prescribing for CNCP. Similar to the survey conducted in 2010, the top two factors were access to patients' opioid prescription history from provincial monitoring program ( $88 \%$ in 2018 and $87 \%$ in 2010), and improved access to pain or addiction specialists ( $87 \%$ in 2018 and 84\% in 2010). The third top factor in 2018 was availability of non-pharmacological options ( $85 \%$, a new factor added only in the 2018 survey). The other factor that tied in second in 2010 was knowledge of risks and benefits of different opioids (84\%).

The main limitations of this study are very similar to the limitations reported in 2010. All response are self-reported practices, however, respondents reported infrequently conducting practices included as "distracters", suggesting credence to the findings. The number of responses represents a small proportion of the 45,000 family physicians who practice in Canada. We received no response of the French version of the survey. The geographical distribution was unbalanced with majority of 
respondents from the province of Saskatchewan. We used a non-probability convenience sample which limits the generalizability of our findings. In the absence of a clear definition of what is a pain specialist or an addiction specialist, it is difficult to validate the answers about wait times to specialists. Finally, we did not ask questions about respondents' exposure to or use of the guideline or their opinions of it.

The demographics of the physicians who participated in this survey have similarities and differences with the 2018 demographics distribution of Canadian family physicians: In our survey, 55\% were male, compared to $53.4 \%$ in Canada [10]. However, in our survey, 30\% work in rural settings, compared to only $8 \%$ in Canada [13].

This survey provides a snapshot of family physicians' current opioid-prescribing practices, opioid guideline knowledge and concordance. One very serious knowledge gap is the lack of understanding about switching patients to transdermal fentanyl, a very potent, high dose opioid that has the potential to cause overdose quickly. It is very concerning that there are still $52 \%$ of respondents who did not get the correct response to this question. This indicates there is still a great need for knowledge translation, exchange, and education in how to prescribe opioids for patients with chronic pain.

It would be informative to repeat this survey at regular intervals in two to five years to detect changes over time; however, this will have to take account of the changes in format and recommendations of updated guidelines. These national surveys are attempts to assess if the release of opioid guidelines has been achieving the changes that they proposed to make. If the survey is repeated regularly it may be possible to establish ongoing relationships with provincial and national organizations to distribute it more widely and encourage participation. It is important to seek support and endorsement of organizations such as the College of Family Physicians of Canada and the medical regulatory authorities.

\section{Conclusions}

This survey represents a small proportion of family physicians in Canada and its generalizability is limited. However, we identified a number of opioid-related and guideline-specific knowledge gaps, areas where the Canadian opioid guideline's recommendations are not being adhered to, barriers and enablers to prescribe opioids, and to adherence to the guideline.

Supplementary Materials: The following are available online at http:/www.mdpi.com/2077-0383/9/10/3304/s1, Supplementary Materials S1: Survey of Canadian Family Physicians about treatment of patients with chronic pain, Supplementary Materials S2: Sondage aupres des medecins de famille canadiens, Table S1: Rating of factors affecting decision not to prescribe strong opioids for chronic noncancer pain, Figure S1: Responses to the open-ended question "At what daily dose of morphine or equivalent do you consider that patients might need to be referred for a second opinion?".

Author Contributions: Conceptualization, M.A. and A.D.F.; methodology, M.A., A.D.F., S.D., P.M. and A.C.; formal analysis, A.D.F. and S.D.; investigation, S.D.; resources, A.D.F.; data curation, A.D.F. and S.D.; writing—original draft preparation, A.D.F.; writing-review and editing, A.D.F., S.D., A.C., P.M. and M.A.; supervision, M.A. and A.D.F.; project administration, S.D.; funding acquisition, A.D.F. All authors have read and agreed to the published version of the manuscript.

Funding: This study was conducted with support from CONACyT (Mexican National Council for Science and Technology) for funding Santana Diaz to participate in this study and Health Canada, Substance Use and Addictions Program (SUAP) for funding the survey. Furlan has nothing to disclose.

Acknowledgments: The authors would like to thank the physicians who responded the survey.

Conflicts of Interest: The authors declare no conflict of interest.

\section{References}

1. Schopflocher, D.; Taenzer, P.; Jovey, R. The prevalence of chronic pain in Canada. Pain Res. Manag. 2011, 16, 445-450. [CrossRef] [PubMed]

2. Chou, R.; Turner, J.A.; Devine, E.B.; Hansen, R.N.; Sullivan, S.D.; Blazina, I.; Dana, T.; Bougatsos, C.; Deyo, R.A. The effectiveness and risks of long-term opioid therapy for chronic pain: A systematic review for a National Institutes of Health Pathways to Prevention Workshop. Ann. Intern. Med. 2015, 162, 276-286. [CrossRef] 
3. Canadian Institute for Health Information. Opioid Prescribing in Canada: How Are Practices Changing? 2019. Available online: https://www.cihi.ca/sites/default/files/document/opioid-prescribing-canada-trendsen-web.pdf (accessed on 13 October 2020).

4. Canadian Centre for Substance Abuse. Opioids. Available online: https://www.ccsa.ca/opioids (accessed on 2 March 2020).

5. Public Health Infobase. Opioid-Related harms in Canada Published. Available online: https://healthinfobase.canada.ca/substance-related-harms/opioids/ (accessed on 25 September 2020).

6. Crabtree, A.; Lostchuck, E.; Chong, M.; Shapiro, A.; Slaunwhite, A. Toxicology and prescribed medication histories among people experiencing fatal illicit drug overdose in British Columbia, Canada. Can. Med. Assoc. J. 2020, 192, E967-E972. [CrossRef]

7. Allen, M.J.; Asbridge, M.M.; Macdougall, P.C.; Furlan, A.D.; Tugalev, O. Self-reported practices in opioid management of chronic noncancer pain: A survey of Canadian family physicians. Pain Res. Manag. 2013, 18, 177-184. [CrossRef]

8. Furlan, A.D.; Reardon, R.; Weppler, C. Opioids for chronic noncancer pain: A new Canadian practice guideline. Can. Med. Assoc. J. 2010, 182, 923-930. [CrossRef] [PubMed]

9. Busse, J.W.; Craigie, S.; Juurlink, D.N.; Buckley, D.N.; Wang, L.; Couban, R.J.; Agoritsas, T.; Akl, E.A.; Carrasco-Labra, A.; Cooper, L.; et al. Guideline for opioid therapy and chronic noncancer pain. Can. Med. Assoc. J. 2017, 189, E659-E666. [CrossRef] [PubMed]

10. Canadian Institute for Health Information. Physicians in Canada. 2019. Available online: https://www.cihi. $\mathrm{ca} /$ sites/default/files/document/physicians-in-canada-2018.pdf (accessed on 13 October 2020).

11. Marshall, E.G.; Burge, F.; Gibson, R.J.; Lawson, B.; O' Connell, C. Accepting new patients who require opioids into family practice: Results from the MAAP-NS census survey study. BMC Fam. Pract. 2019, 20, 141. [CrossRef] [PubMed]

12. Leece, P.; Shantharam, Y.; Hassam, S.; Buchman, D.Z.; Hamilton, M.; Persaud, N.; Kahan, M.; Spithoff, S.; Srivastava, A.; Sproule, B.A.; et al. Improving opioid guideline adherence: Evaluation of a multifaceted, theory-informed pilot intervention for family physicians. BMJ Open 2020, 10, e032167. [CrossRef] [PubMed]

13. Charbonneau, G. Recruiting physicians to practise in rural communities. Can. Fam. Physician 2018, 64, 621. [PubMed]

Publisher's Note: MDPI stays neutral with regard to jurisdictional claims in published maps and institutional affiliations.

(C) 2020 by the authors. Licensee MDPI, Basel, Switzerland. This article is an open access article distributed under the terms and conditions of the Creative Commons Attribution (CC BY) license (http://creativecommons.org/licenses/by/4.0/). 